\title{
COMPREENDENDO OS MOVIMENTOS CONSTRUTIVOS DA DOCÊNCIA SUPERIOR: CONSTRUCCÕES SOBRE PEDAGOGIA UNIVERSITÁRIA
}

\author{
UNDERSTANDING THE CONSTRUCTIVE MOVEMENTS \\ OF HIGHER EDUCATION TEACHING: CONSTRUCTIONS \\ OVER UNIVERSITY PEDAGOGY \\ COMPRENANT LES MOUVEMENTS CONSTRUCTIFS \\ DE L'ENSEIGNEMENT UNIVERSITAIRE : CONSTRUCTIONS \\ SUR LA PÉDAGOGIE UNIVERSITAIRE \\ COMPRENDIENDO LOS MOVIMIENTOS CONSTRUCTIVOS \\ DE LA DOCENCIA SUPERIOR: CONSTRUCCIONES \\ SOBRE PEDAGOGÍA UNIVERSITARIA
}

\author{
Silvia Maria de Aguiar Isaia * \\ Doris Pires Vargas Bolzan **
}

\begin{abstract}
RESUMO
Esse artigo decorre de pesquisas que as autoras vêm desenvolvendo em especial sobre a temática dos ciclos de vida profissional de professores do ensino superior. Discute os possiveis movimentos construtivos na trajetória docente de professores universitários. Essa discussão se dá a partir da busca pela compreensão dos movimentos construtivos da docência, bem como do delineamento de possiveis ciclos de vida profissional desses sujeitos. Os participantes da pesquisa foram agrupados considerando-se o tempo de experiência no magistério superior, com a finalidade de narrarem suas biografias. Nesta análise encontramos quatro movimentos construtivos da docência: preparação à carreira docente; entrada efetiva no magistério superior; marcas da pós-graduação na docência superior; professoralidade docente. Os achados permitem-nos especular que os fios das concepçôes de docência são tecidos a partir dos movimentos construtivos ao longo da trajetória docente, demarcando-os como um processo contínuo de aprendizagem docente.
\end{abstract}

Palavras-chave: Pedagogia universitária. Movimentos construtivos. Docência superior.

* Doutora em Educação pela Universidade Federal do Rio Grande do Sul (UFRGS, 1992). Professora do Programa de Pós-Graduação em Educação da Universidade Federal de Santa Maria (UFSM). Professora Pesquisadora da Unifra. Bolsista do CNPq. Coordenadora da Ries na UFSM. Membro do Pronex CNPq/Fapergs e do Observatório da Educação Capes/Inep (sisaia@terra.com.br).

** Doutora em educação pela UFRGS (2002). Professora do Programa de Pós-Graduação em Educação da UFSM. Coordenadora do Programa de Pós-Graduação em Educação CE/UFSM. Membro da Ries e Pesquisadora Participante do Observatório da Educação junto à UFSM (professoradoris@smail.ufsm.br). 


\section{PALAVRAS INTRODUTÓRIAS}

Este artigo decorre de pesquisas desenvolvidas pelas autoras. Dentre os projetos desenvolvidos destaca-se o relativo ao estudo dos ciclos de vida profissional de docentes do ensino superior em que buscamos desvelar os movimentos construtivos desses sujeitos. Para tanto, o campo da pesquisa escolhido foi uma Universidade Federal, congregando os professores dos Cursos de Licenciatura e de Bacharelado.

Neste texto, a temática nos remete as seguintes indagaçôes: Quais os movimentos construtivos da docência superior? Quais os elementos constitutivos nos movimentos encontrados?

$\mathrm{Na}$ tentativa de responder a essas questôes encontramos três razões principais. A primeira ancora-se na necessidade de um estudo sistemático que leve em conta a especificidade da de uma Pedagogia Universitária. Os estudos já realizados, mesmo contemplando as noçōes de Huberman $(1989,1998)$ não estão voltados, estrito senso, para o estabelecimento de movimentos construtivos relativos à docência superior e pesquisadores brasileiros apenas aplicam o modelo hubermasiano a seus estudos com docentes universitários (LUDKE, 1996; MIZUKAMI, 1995, 1996). A segunda, porque, paradoxalmente, ao mesmo tempo em que os professores são vistos como responsáveis pela formação de um leque diversificado de profissionais, voltados tanto para as profissões liberais quanto para a docência, sua formação docente não tem sido valorizada nas IES. Basta ver que a titulação e a produção científica são os critérios distintivos para a progressão na carreira docente, não garantindo, contudo, um ensino de qualidade (ISAIA, 2003, 2006a; ISAIA; BOLZAN 2006; ZABALZA, 2004).

Em nossos estudos constatamos que os docentes que atuam na docência superior, em sua maioria, tiveram sua formação na área específica de seu bacharelado e/ou licenciatura, sem, contudo terem qualquer atividade ou disciplina curricular que os preparasse pedagogicamente para atuar na Educação Superior. Logo, todo o processo formativo instaurado durante a formação inicial não dá conta da carreira Universitária. Advém daí outra indagação relevante: quem forma ou como se formam estes docentes? Uma possibilidade de resposta vincula-se à questão das trajetórias ao longo da carreira docente, na medida em que sua formação docente precisa ocorrer ao longo de um processo continuado e em serviço.

A terceira, porque entendemos, com base em pesquisa já realizada, que as concepçôes de docência podem ser os fios condutores para se entender as transformaçóes ocorridas na prática educativa desses professores, caracterizando-se a partir daí seus movimentos construtivos e, conseqüentemente os ciclos profissionais pelos quais passam ou podem passar. Em nossa compreensão, essas envolvem a noção de como os professores percebem e pensam a docência, envolvendo criação mental e possibilidade de compreensão. Elas comportam, assim, dinâmicas em que se articulam processos reflexivos e práticas efetivas em permanente movimento construtivo ao longo da carreira docente. Emergem da 
vivência dos professores, apresentando componentes explícitos e implícitos que envolvem tanto saberes advindos do senso comum, como do conhecimento sistematicamente elaborado e organizado. Neste sentido, essas concepções são atravessadas por expectativas (projeções), sentimentos, apreciações que acompanham a linha temporal da trajetória docente, tanto em termos retrospectivos quanto prospectivos, constituindo assim, os ciclos da profissão. Desse modo, essas concepções orientam a visão que os docentes têm de si mesmos em situação de sala de aula, dos alunos, do seu fazer pedagógico, dos colegas e da instituição a que pertencem (ISAIA, 2006b).

Com vista às questóes por nós levantadas, optamos, nesse texto, em apresentar um recorte da pesquisa sobre os ciclos. Esse se orienta pelo objetivo de apreender o movimento construtivo dos ciclos de vida profissional dos docentes participantes, considerando-se suas percepções sobre a carreira, permeadas pelas concepções de docência que vão construindo ao longo de suas atividades como professores. Com esse intuito utilizamos o corpus relativo às auto-reconstruçôes biográficas elaboradas por escrito, por um grupo de vinte docentes de instituição pública. Esse procedimento metodológico teve por finalidade levar os professores a reconstruírem, via memória, suas trajetórias docentes, demarcando as fases das mesmas, suas principais características e a temática que as orienta.

Como nosso objetivo é apreender o movimento construtivo dos ciclos de vida profissional docente, levamos em conta o tempo de experiência destes sujeitos no magistério superior, classificando este percurso em: anos iniciais (0-5), anos intermediários (6-15) e anos finais (de 16 anos em diante). O material decorrente das auto-reconstuções foi trabalhado a partir da análise de conteúdo (BAUER, 2004; MORAES, 1998).

Desse modo, buscamos, a partir das narrativas dos professores, descrever e interpretar os relatos escritos que eles fazem dos acontecimentos vividos ao longo da carreira docente e, assim, tentar compreender como esses repercutem no movimento transformacional das concepções de docência que adotam.

Portanto, o ponto focal desse estudo está em partir da subjetividade dos docentes, ou seja, de como eles percebem e interpretam suas trajetórias docentes. Tratamos, assim, de produzir novos significados sobre o processo construtivo dos professores, partindo de um duplo movimento interpretativo, envolvendo, por um lado, os pesquisadores e, por outro, os docentes, sujeitos da pesquisa. Tal procedimento, dentro da tradição narrativa, levou em conta, conforme Arnaus (1995), os que contam e nós que interpretamos, compreendendo assim, não só como os professores relatam suas vidas, mas também como nós os pesquisadores narramos e interpretamos esses relatos (CONNELLY; CLANDININ, 1995).

Reiteramos que a opção pelo viés narrativo se deu na medida em que não só são dadas voz e vez aos professores envolvidos no estudo, mas também a possibilidade desses tomarem distância de suas vidas profissionais, convertendo-as em objeto de auto- 
reflexão, podendo assim, [re] significá-las e transformá-las (HUBERMAN, 1989, 1998; McEWAN, 1998).

Nessa direção é que pretendemos tramar os fios teóricos e empíricos relativo à investigação dos ciclos, buscando apreender os prováveis percursos que os movimentos construtivos da docência tomam e as temáticas subjacentes a esses, ao longo da carreira docente, levando em conta as concepções de docência construídas.

\section{FIOS TEÓRICOS ORIENTADORES}

O ponto inicial que nos orienta é a noção do professor como pessoa, a partir dos estudos desenvolvidos por Abraham $(1987,2000)$ que enfatizam a necessidade de pesquisas que consideram a inter-relação entre aspectos pessoais e profissionais. Ambos os aspectos remetem a compreensão de que o processo formativo é de natureza social, pois os professores se constituem como tal em atividades interpessoais, seja em seu período de preparação, seja ao longo da carreira, em uma ou em diferentes IES. Os esforços que eles realizam para aquisição, desenvolvimento e aperfeiçoamento de competências profissionais, subentendem um grupo interagindo, centrado em interesses e necessidades comuns, em um contexto institucional concreto.

Nesse sentido, destacamos a necessidade de estudos que levem em conta a trajetória vivencial dos professores e o modo como eles articulam o pessoal, o profissional e o institucional e, conseqüentemente, como vão se (trans)formando, no decorrer do tempo.

Nesse viés investigativo o professor é visto como sujeito de sua própria vida e do processo educativo do qual é um dos atores. Tal perspectiva não implica em desinteresse pelas condições conjunturais que o cercam, mas acreditamos que essas precisam ser pensadas a partir da forma como são vividas e apreendidas pelos docentes. Daí a importância das vozes dos professores narrando suas próprias histórias - autoreconstrução biográfica.

Ao analisarmos as narrativas dos docentes participantes, levamos em conta que as concepções de docência nelas presentes, comportam dinâmicas em que se articulam processos reflexivos e práticas efetivas, em permanente movimento construtivo ao longo da carreira. Assim, a docência constitui-se como um espaço para além da dimensão técnica, sendo atravessada não só por conhecimentos, mas também por relações interpessoais e vivências de cunho afetivo, valorativo e ético, como nossos achados têm demonstrado.

Outro elemento conceitual, para as trama dos fios teóricos, é a noção de trajetória, percurso, ciclo de vida, embasada em Ortega y Gasset (1970). O percurso vital pode, assim, ser entendido como etapas, idades vividas, em que cada docente vai transitando em porções de tempo que vão se sucedendo. O importante é que esta sucessão de momentos existenciais não só ocorrem uns após os outros, mas principalmente, se 
enlaçam, resultando no que o filósofo espanhol denomina de geração. Essa envolve um conjunto de anos vivenciados por um grupo de pessoas que compartilham entre si valores, crenças e estilos de vida, mas que convivem em um mesmo momento histórico, com outras geraçôes. Esta concepção de geração foi transposta e ampliada a partir de nossos estudos, denominando-se de geração pedagógica. Essa se constitui em um conjunto de professores que se situam em uma mesma dimensão temporal e compartilham, entre si, valores, crenças, convicçōes e estilos próprios de entender e viver a docência (ISAIA, 2006b, 368).

Assim, a trajetória profissional dos professores do ensino superior envolve uma multiplicidade de geraçôes pedagógicas que não só se sucedem, mas se entrelaçam em um mesmo percurso histórico, possuindo, contudo, modos diferenciados de participação, interação e compreensão da trajetória formativa a ser empreendida pelos docentes nas instituições em que atuam. As possíveis resistências ao logo dessa trajetória podem ser em decorrência da assincronia geracional entre os diversos grupos de professores, o que pode indicar a necessidade da mesma ser levada em conta para o planejamento e a implementação do desenvolvimento profissional docente.

Em termos profissionais este percurso corresponde à carreira pedagógica ou, como denominamos em nossas pesquisas de trajetória docente. Esta é entendida como um processo que envolve a trajetória especificamente docente dos professores em uma ou em várias instituições de ensino, nas quais estiveram ou estão engajados e que, de algum modo, condiciona as açôes formativas que eles realizam, tendo em vista o próprio desenvolvimento e de seus alunos (ISAIA, 2006b). O significativo a considerar é que a carreira é influenciada, tanto pelas características pessoais (trajetória de vida) dos professores, quanto pelas profissionais (contexto institucional em que estão inseridos). Nesse sentido, é importante considerarmos, de modo integrado, as alterações vivenciais e as maneiras como os professores encaram a docência. Assim, a história de vida pessoal e profissional remete à dimensão dos outros, daqueles que precedem e acompanham a cada um, sendo constituída na trama de relações vividas e narradas (BRUN; BACHELART, 2000; LANI-BAYLE, 2000).

Desse modo, o desenrolar da carreira é um processo que, apesar de seqüencial, não se apresenta de forma linear, daí os ciclos de vida profissional corresponderem aos momentos de ruptura ou oscilação, responsáveis pelo aparecimento de novas fases ou percursos que podem ser trilhados pelos docentes. (HUBERMAN, 1989, 1998). Os ciclos abarcam, deste modo, uma sucessão de anos combinados com fases que podem apresentar mais de uma temática e, para cada fase, entradas e saídas diversificadas ao longo da carreira docente. Mesmo que haja certa estandardização seqüencial, constatamos que os acontecimentos dentro de cada etapa são percebidos e enfrentados de forma idiossincrática pelos professores. Essa seqüência não linear e que carrega as peculiaridades de cada docente e de como ele interpreta os acontecimentos vividos corresponde ao que denominamos de movimentos construtivos da docência. 
Nessa perspectiva buscamos compreender esses movimentos a partir da percepção que cada docente tem de sua carreira, tendo como fio condutor a subjetividade de cada um e como constroem as concepções de docência em sua trajetória constituída pelos seus diferentes ciclos profissionais.

\section{DISCUSSÃO DOS ACHADOS: ENTRELAÇAMENTO DE FIOS TEÓRICOS E EMPÍRICOS}

Os docentes responsáveis pelas auto-reconstruções receberam siglas relativas aos anos de experiência no magistério superior, a fim de ser resguardado seu anonimato. Assim, os professores dos anos iniciais receberam a sigla $P A I$, os dos anos intermediários são indicados pela sigla $P A T$ e os dos anos finais são representados pela sigla $P A F$. Os vinte professores se distribuíram numericamente do seguinte modo, quanto ao tempo da carreira docente: cinco para os anos iniciais; sete para os anos intermediários e oito para os anos finais. O maior número de sujeitos contemplados nos anos intermediários e finais se deve ao fato de que estes possuem uma trajetória docente que nos permitiu compreender de forma mais detalhada os movimentos transformativos por que passam e no delineamento de suas trajetórias ${ }^{1}$ foi o grupo mais expressivo, ou seja, o que apresentou maior percentual do grupo como um todo.

Com base nas vinte auto-reconstruções biográficas, procuramos evidenciar quais os movimentos que os professores participantes perceberam em suas trajetórias docentes, buscando os primeiros indicadores de possíveis movimentos construtivos.

\section{Preparação à carreira docente}

Esse movimento envolve experiências no ensino médio, monitorias, estágios de residência médica, curso de pós-graduação "latu sensu" e "strito sensu", atuação como professor substituto e influências familiares, denotando que a trajetória profissional docente vai se constituindo a partir de experiências prévias que podem direcionar futuramente o sujeito para a carreira docente.

(...) Escola Normal Colegial como professora primária por dois anos (...) professora contratada, de língua inglesa de $5^{\mathrm{a}}$ a $8^{\mathrm{a}}$

(...) alunos eram filhos dos empregados das empreiteiras responsáveis pela obra (...) PAF.

(...) Aparece como substituta (...) 1995 - substitutos heróis - número de disciplinas diferentes com enfoques distintos. (...) Não questionava a falta de qualidade de ensino e a baixa remuneração (...). Orgulho por ter um contrato com a (...) PAI.

(...) forma de estudar era em grupo e geralmente ensinando colegas, para o vestibular (...) estudei com uma colega que tinha facilidade em disciplinas matemáticas e eu em outras e nos ensinávamos, trocávamos conhecimentos. (...) este histórico preparou o terreno para a docência (...) PAT. 
Os professores participantes demarcaram que neste período inicial começam a se dar conta da docência superior como uma possibilidade, apesar de que a maioria ainda não explicita com clareza que tinha consciência de que iria dedicar-se a este nível de ensino. Salientamos que este período constituiu-se em uma formação inicial para a futura carreira, pois é a partir dele que os docentes entraram em contato, pela primeira vez, com a dinâmica educativa.

Podemos perceber a partir deste primeiro movimento o que temos denominado de aprendizagem docente ${ }^{2}$, ou seja, o processo de apropriação, por parte do professor, de saberes e fazeres inerentes a uma Pedagogia Universitária.

\section{Entrada efetiva no magistério superior}

Esta entrada ocorre de forma circunstancial para grande parte dos professores, não representando uma escolha efetivamente buscada para o início da vida profissional, mas, principalmente, pela oportunidade de trabalho que representa.

Para outros, contudo, o magistério é uma a escolha pessoal, o que indica um forte componente de envolvimento afetivo com a docência desde um período prévio. Um fator preponderante nesta escolha encontra-se em uma inclinação afetiva que denominamos, a partir de resultados de nossas pesquisas, de sentimentos docentes. ${ }^{3}$ Eles podem constituirse na escolha profissional e, principalmente, ao logo da docência, em elementos dinamizadores da atividade educativa dos professores. Nas narrativas dos docentes foi possível detectarmos a explicitação destes sentimentos:

(...) Não sei, hoje, se meu início na vida docente foi por falta de outras opções; eu tinha então, 26 anos, queria muito trabalhar, não tinha outro convite e planejava ter filhos, e, portanto, um emprego público seria um bom início (...) PAF.

(...) A minha motivação para exercer a docência era ter um trabalho e poder me desenvolver como pessoa e profissionalmente. Não sabia bem o que significava ser professor PAF.

(...) Agora me parece que para docência não houve uma escolha, mas que ela estava dentro de mim e aflorou (...) PAT.

(...) logo no início do mestrado, soube da possibilidade do concurso na. (...) Havia uma vaga

(...) então, uma possibilidade muito real de ser professor. Tive tempo e me preparei muito para o concurso (...) Começava então a minha carreira docente, como professor auxiliar, além de continuar o mestrado (...) PAT.

Algumas das percepções marcantes deste período envolvem: solidão pedagógica, insegurança frente aos alunos e à disciplina, tanto em termos de manejo de classe, quanto de domínio do conteúdo da disciplina; centração no conteúdo específico e na necessidade de vencer o programa a qualquer custo; inadequação para a docência, ou seja, falta de domínio de uma pedagogia para esse nível de ensino.

A solidão pedagógica é sentida devido à inexistência tanto de apoio institucional ao professor iniciante, quanto da parte de colegas mais experientes. Cunhamos o termo 
solidão pedagógica para indicar o sentimento de desamparo dos professores frente à ausência de interlocução e de conhecimentos pedagógicos compartilhados para o enfrentamento do ato educativo. $\mathrm{O}$ processo de organização pedagógica e sua relação com as açôes do professor constituem o que denominamos de conhecimento pedagógico compartilhado. Esse é um conceito de base centrado em uma rede de relações interpessoais e que compreende o domínio do saber fazer (estratégias pedagógicas) e do saber teórico e conceitual e suas relaçôes. Ele implica em trocas cognitivas e socioculturais entre ensinantes/aprendentes, sendo possível destacarem-se condições a serem levadas em conta pelos professores, ao longo de suas trajetórias de formação (BOLZAN, 2006, p. 380).

A insegurança frente aos alunos ou à disciplina é uma característica comum no início da carreira devido ao despreparo dos professores para a docência superior, na medida em que o preparo para o magistério superior não é contemplado nos currículos dos diversos cursos de graduação e na Pós-graduação "latu ou strito sensu", apenas está presente na forma de disciplinas esparsas, quando ocorrem, ou em iniciativas mais atuais de contemplar a docência orientada ou o estágio da docência como preparação inicial ao nível superior, experiência vivida especificamente pelos alunos que estão fazendo os cursos de mestrado ou doutorado em educação.

A centração no conteúdo específico é uma marca dos professores iniciantes e se estende também àqueles que apresentam maior consolidação da docência, mas com variantes diferenciadas. Esse conhecimento, que os professores tanto valorizam, refere-se aos conhecimentos sobre a matéria a ser ensinada. Constitui-se por elementos conceituais e organizacionais dos conteúdos próprios da disciplina, envolvendo idéias, informações, definições, convenções e tópicos gerais, bem como sua estrutura organizacional. (BOLZAN 2002, 2004; MARCELO GARCÍA, 1999). Assim, é necessário que os professores, além de considerarem seus domínios específicos, invistam na dimensão pedagógica da docência. Essa dimensão envolve atividades e valores traduzidos em: a) sensibilidade frente ao aluno; b) valorização dos saberes da experiência; c) ênfase nas relações interpessoais; d) aprendizagem compartilhada; e) integração teoria/prática; f) o ensinar enfocado a partir do processo de aprender do aluno, tudo isso voltado para o desenvolvimento desse sujeito como pessoa e profissional, constituindo, desse modo, uma pedagogia própria para esse nível de ensino, o que chamamos de pedagogia universitária. ${ }^{4}$

$A$ inadequação à docência decorre da falta de preparo específico para o magistério superior. Isto se deve ao fato, já comentado, de que os docentes mesmo estando cientes da sua função formativa, não consideram a necessidade de uma preparação específica para exercê-la. É como se o conhecimento específico desenvolvido nos anos de formação inicial e mesmo no início da carreira, bem como o exercício profissional bastassem para assegurar um bom desempenho docente. Isso se torna evidente nas narrativas que seguem: 
(...) A estrutura em Centros e Departamentos pulveriza as atividades concentradas (...) A estrutura departamental isola os profissionais omissos e atravanca o desenvolvimento dos que trabalham (...) PAF.

(...) Espaços para a partilha coletiva de experiências pedagógicas não existiam, pelo menos de maneira formal (...) PAT.

(...) Devemos encontrar um modo de trocarmos idéias com os colegas sobre as disciplinas lecionadas, sobre o planejamento das aulas, a forma e a metodologia utilizada para lidar com certos conteúdos, sempre buscando um objetivo comum (...) PAI.

(...) pela falta clássica de informações entre os colegas de disciplina, só se interam dos aspectos administrativos e ou curriculares, os chefes de disciplina (...) Planejamento de aulas, acompanhamento, partilha de experiências pedagógicas não foram abordadas ou discutidas no departamento (...) PAF.

(...) A preocupação era diretamente proporcional ao conteúdo e ao modo de expô-lo, sem nenhuma preocupação quanto à aplicabilidade prática (...) PAF.

Evidenciamos que a idéia de aprendizagem docente implicitamente está presente neste movimento construtivo, na medida em que percebemos a tomada de consciência dos professores de sua inadequação docente, o que lhes permite moverem-se em direção a futuras transformações.

\section{A marca da pós-graduação na docência superior}

Esta experiência pode ser anterior ou após a entrada na carreira docente, mas de qualquer modo marca uma nova perspectiva docente, voltada para a pesquisa, à orientação de alunos, seja de IC, mestrado ou doutorado e para a produção acadêmicocientífica. A Pós-graduação "strictu sensu", representa, sem dúvida, um novo movimento transformativo na construção da carreira docente. Esta construção, possivelmente, envolve o fato de que os critérios de seleção e progressão funcional adotados nas IES estão centrados, principalmente, na titulação e na produção científico-acadêmica como vimos constatando. Salientamos, ainda, que os docentes creditam aos Cursos de Pósgraduação "strictu sensu" a expansão de seus horizontes conceituais e a possibilidade de formarem-se como pesquisadores e como docentes na educação superior, o que lhes dá maior maturidade como professores. Eles explicitaram em suas narrativas a importância deste acontecimento em suas carreiras, inclusive como forma de sentirem-se mais preparados para a docência após sua realização. Esses aspectos deixam evidente o processo de aprendizagem docente que vai sendo tecido nas diferentes vivências da docência. Não é possível pensar no processo de aprender a ser professor sem a efetivação de uma rede de interação que se caracteriza pela atividade compartilhada. A ação, a reflexão conjunta e a negociação de conflitos, favorecem a construção de uma rede de relações que compõe o processo interativo da formação docente e seu conseqüente processo de aprendizagem compartilhada, possibilitando a aprendizagem da docência e, conseqüentemente, o desenvolvimento profissional no ensino superior (BOLZAN, 2002, 
2004; BOLZAN; ISAIA, 2006; ISAIA; BOLZAN, 2006; 2007a e b). As narrativas que seguem evidenciam esses elementos.

(...) os projetos de pesquisa sob minha coordenação sempre tiveram como colaboradores apenas estudantes do curso (...) (às vezes de outras áreas da saúde). Portanto, o ensino vinha na esteira da produção acadêmica, assim como a extensão (assistência para nós) (...) PAF.

(...) tive contato com professores e autores que me oportunizaram pensar de forma diversa, considerar coisas que eu não havia considerado, perceber certas nuances que me escapavam. Cresci muito ao longo deste meu ainda curto percurso dentro da educação. As mudanças são enormes, tenho muito mais tranqüilidade hoje em tratar com os meus alunos. Gosto muito mais de ser professor hoje do que antes de ter contato com a Educação (...) PAI.

(...) foi iniciar sob "nova roupagem acadêmica" uma atividade docente diferente daquela quando comecei a lecionar. Novas idéias, novas técnicas de ensinagem, trabalho acadêmico centrado no aluno, como foco primeiro da minha atenção, com repercussão direta sobre o produto final da atividade (...) a questionar, discutir, pesquisar, envolver, etc. era algo que fugia completamente ao paradigma até então estabelecido (...) PAF.

(...) Enquanto isso, na pós-graduação, matriculei-me em duas disciplinas de educação, Fundamentos Educacionais do Ensino Superior e Didática do Ensino Superior. A primeira foi excelente, me fez começar a ver com outros olhos a licenciatura e o ensino (...) PAT.

\section{Professoralidade docente}

Nesse movimento o conteúdo não parece ser o mais importante. Os professores estão mais voltados para as necessidades dos alunos do que de suas próprias. $\mathrm{O}$ amadurecimento profissional e a consciência de que a docência é um processo construído ao longo da carreira parece ser o elemento distintivo. Esta consciência depende de que os docentes tenham um conhecimento consistente de sua área de conhecimento; do modo como seus alunos aprendem e de com podem ser auxiliados neste processo, o que, sem dúvida, mobiliza movimentos de reorganização do trabalho pedagógico da aula universitária.

Devido às peculiaridades desse movimento, nós o denominamos de professoralidade docente na medida em que ela implica não só em dominar conhecimentos, saberes, fazeres de determinado campo, mas envolve também a sensibilidade do docente como pessoa e profissional em termos de atitudes e valores, levando em conta os saberes da experiência docente e profissional, entendida a partir de uma ótica de reflexão sistemática, bem como a ênfase nas relações interpessoais, entendidas como o componente intrínseco ao processo de ensinar, aprender, formar-se e, conseqüentemente, desenvolverse profissionalmente (BOLZAN; ISAIA, 2006).

Assim o professor à medida que ensina aprende com seus alunos, denotando espírito de abertura e humildade ao não adotar uma posição autoritária, ao mesmo tempo em que está ciente de sua responsabilidade em conduzir o processo formativo dos alunos, tendo como meta o desenvolvimento dos mesmos, como pessoas e profissionais. Com esta postura o professor está assumindo a professoralidade docente (ISAIA; BOLZAN, 2006, 2007a, 2007b). 
Nessa mesma direção, afirmamos que outro elemento essencial a professoralidade é a certeza do inacabamento, isto é, o professor para se construir na docência precisa estar disposto a aprender. Não estamos falando de uma aprendizagem generalizada de ser professor, mas a entendemos a partir do contexto concreto de cada um, tendo em vista sua trajetória de formação, sua trajetória institucional e para qual atividade formativa está direcionado. Nesse processo estão implicados a dinamização dos conteúdos específicos da área disciplinar e os modos de construção de estratégias pedagógicas para o desenvolvimento de atividades de estudo a serem implementadas, compreendidos por nós como elementos fundantes do processo de aprender a docência.

Para tanto, é necessário levarmos em conta o que entendemos por docência. Assim, nós a definimos como todas as atividades desenvolvidas pelos professores, orientadas para a preparação de futuros profissionais. Dessa forma, a docência superior precisa apoiar-se na dinâmica da interação/compartilhamento de diferentes processos que respaldam o modo como os professores concebem o conhecer, o fazer, o ensinar, e o aprender, bem como o significado e o sentido que dão a eles. Portanto, a docência superior ocorre no espaço de articulação entre modos de ensinar e de aprender, constituído por uma pedagogia universitária própria, em que professores e alunos intercambiam as funções de ensinantes e de aprendentes. Nesse sentido, podemos falar em aprendizagem compartilhada, seja relativa ao processo construtivo de ser professor do ensino superior, seja em relação ao processo inicial de preparação dos alunos como futuros profissionais em suas diversas áreas de atuação relativas aos cursos de licenciatura e de bacharelado a que estão ligados. Tais elementos se evidenciam nas narrativas colhidas.

(...) Tenho projetos de ensino, pesquisa e extensão. Estão ligados a formação (...)nos cursos de graduação em um movimento nacional e a criação de espaços para informaçôes, reflexôes que auxiliem na revisão das concepçôes que embasam as mudanças desejadas no setor saúde, como a própria concepção de saúde. Na pesquisa estudo a tendência de mudanças nos cursos de graduação das escolas médicas brasileiras. Estas atividades, sendo fora do âmbito da docência do curso, estão dentro das propostas de uma universidade. (...) Penso que a docência que trata do ensino, não pode estar desvinculada da pesquisa e extensão/assistência. (...) PAF.

(...) hoje considero o "ser professor" o centro da minha vida profissional. Acho que muitas coisas estão mudando e tantas outras ainda vão mudar. Atuo como docente em função dos alunos, a interação com eles é o meu principal motivador. E das discordâncias com os colegas, tiro muitas liçōes. Acho que o principal atributo de um professor é a capacidade de considerar alternativas. E isso não é nada fácil. Mas, como já disse anteriormente, ninguém disse que seria (...) PAI.

(...) sempre dou importância ao conteúdo a ser ministrado, mas também me preocupo com o modo de ensinar. A aplicação futura dos conteúdos também é levada em consideração, sobretudo aos alunos de cursos de licenciatura (...) PAT. 


\section{APONTAMENTOS FINAIS: UMA CAMINHADA POSSÍVEL À COMPREENSÃO DOS MOVIMENTOS CONSTITUTIVOS DOS CICLOS}

Com base em achados desta etapa da pesquisa, evidenciamos que as concepções de docência de professores de licenciatura e de bacharelado de uma IES pública vão se transformando, permeadas por movimentos construtivos que os docentes vão produzindo ao longo da carreira.

Desse modo, o primeiro movimento é de cunho preparatório para a efetiva atuação na universidade. As experiências prévias de caráter pedagógico que eles vivenciam têm a função de iniciá-los na atividade docente futura. Percebemos aí um tateamento em direção a uma função que mais tarde irá se concretizar. Ainda não uma clara idéia sobre quais caminhos trilhar para a produção de uma aula universitária. (adequação das propostas pedagógicas sem ênfase na reprodução de conteúdos específicos apenas). $\mathrm{O}$ segundo movimento envolve a efetivação na docência superior na qual a característica mais marcante é a falta de preparação específica para este nível de ensino. Grande parte das escolhas é acidental na busca de iniciar uma atividade laboral após a graduação. Também evidenciamos a ausência de clareza sobre quais os rumos da atividade docente, uma vez que as exigências não são claramente explicitadas pelas instâncias institucionais (as chefias entregam o ementário e o docente precisa dar conta de realizar a aula sem qualquer tipo de auxílio para tal). O terceiro movimento que os professores explicitam como marcante em sua trajetória docente é a realização de Cursos de Pós-graduação, entendendo-os não apenas como oportunidade de formação para a pesquisa, mas também para a docência na universidade. Essa experiência se caracteriza para muitos dos entrevistados como um caminho formativo em andamento. A partir dos Cursos de Pósgraduação, os nossos sujeitos sentiram-se mais preparados para atuar como professores, percebendo que suas atividades docentes, muito mais do que técnicas, são de natureza pedagógico-formativa em relação aos alunos e a eles próprios. Nessa fase é evidente que os conhecimentos e discussões sobre a área pedagógica vivenciados em disciplinas dos cursos de pós-graduação servem de base para pensar sobre o que produzir em uma aula universitária. O último movimento construtivo demarcado pelos professores envolve o que podemos denominar de professoralidade docente, ou seja, os professores estão engajados em atividades educativas voltadas para o efetivo desenvolvimento de seus alunos. (BOLZAN; ISAIA, 2006). Neste movimento parece emergir uma concepção de docência mais madura, à medida que os saberes por eles acionados estão marcados pela dimensão humana, ou seja, os alunos são os focos de atenção docente, levando-nos a indicar o caráter gerativo desta atividade. Há um evidente direcionamento na organização da aula universitária, uma vez que os docentes consideram as áreas de interesse dos alunos para aprofundar temas e tópicos, o que lhes exige dar conta de tais demandas, obrigando-os a reorganizar o trabalho pedagógico tomando esses aspectos como rele- 
vantes para a dinamização da aula.

Portanto, o professor gerativo caracteriza-se pela postura de engajar-se frente ao desafio de formar seus alunos, isto é, assumir conscientemente a condução pedagógica e colocar em marcha um processo de ação docente que favorece a aprendizagem dos alunos, preparando-os para seu aperfeiçoamento profissional. Ele não apenas executa as atividades docentes, mas sente-se comprometido a realizá-las da melhor forma possível.

Um elemento importante de análise e interpretação para a compreensão dos movimentos construtivos encontrados está em que eles apresentam dimensões contínuas a todo o processo, e outras descontínuas, estando presentes em um ou outro movimento. Assim, elementos próprios à professoralidade podem estar presentes em etapas anteriores, mesclados com elementos contraditórios a esse movimento. Como os movimentos não são lineares e de seqüência fixa, os anos na carreira não são condicionantes suficientes ao surgimento de determinado movimento. Assim, um professor nos anos iniciais da carreira pode apresentar peculiaridades de um maior amadurecimento docente, enquanto outro dos anos intermediários ou finais pode manter características mais comuns a um professor iniciante.

Não podemos esquecer também que os apontamentos, expressos através do esboço de análise preliminar a que chegamos, indicam que as concepçôes de docência envolvem um processo de construção que é marcado por diferentes movimentos construtivos dos professores sujeitos desta pesquisa e dependem da interação dos processos formativos que eles colocam em andamento, da própria aprendizagem da docência que os acompanha ao longo de toda a carreira e de uma pedagogia própria a esse nível de ensino.

\section{Notas}

1. O projeto em sua primeira fase apresentou um número expressivo de docentes que se encontravam na fase intermediária e final da carreira e que responderam a um questionário disponibilizado a todos os docentes. Desses $43 \%$ encontravam-se entre os anos intermediários e finais.

2. Aprendizagem docente compreende um processo interpessoal e intrapessoal que envolve a apropriação de conhecimentos, saberes e fazeres próprios ao magistério superior, que estão vinculados à realidade concreta da atividade docente em seus diversos campos de atuação e em seus respectivos domínios. Sua estrutura envolve: o processo de apropriação, em sua dimensão interpessoal e intrapessoal; o impulso que a direciona, representado por sentimentos que indicam sua finalidade geral; o estabelecimento de objetivos específicos, a partir da compreensão do ato educativo e, por fim, as condiçôes necessárias para a realização dos objetivos traçados, envolvendo a trajetória pessoal e profissional dos professores, bem como o percurso trilhado por suas instituiçôes. A aprendizagem docente ocorre no espaço de articulação entre modos de ensinar e aprender, em que os atores do espaço educativo superior intercambiam essas funçóes, tendo por entorno o conhecimento profissional compartilhado e a aprendizagem colaborativa. Não é possível falar-se em um aprender generalizado de ser professor, mas entendê-lo a partir do contexto de cada docente no qual são consideradas suas trajetórias de formação e a atividade 
formativa para a qual se direcionam (ISAIA, 2006b, p. 377).

3. Os sentimentos docentes constituem-se em elementos dinamizadores da atividade educativa dos professores, uma vez que representam vivências afetivas de caráter apreciativo, o que condiciona a atitude valorativa destes frente ao que é importante ao mundo pessoal e profissional. Envolvem uma dinâmica entre as experiências, competências e expectativas próprias a cada docente em relação a valores, a expectativas e a normas elaboradas no contexto em que estão inseridos. Os processos formativos necessitam de sentimentos orientativos para sua consecução, levando professores e alunos a perceberem suas trajetórias de formação como significativas em termos de realização pessoal e profissional (ISAIA, 2006b, p. 373).

4. Pedagogia Universitária vista como campo polissêmico de produção e aplicação dos conhecimentos pedagógicos na educação superior. Notas: Reconhece-se no plural, como pedagogias múltiplas, porque faz interlocução com os distintos campos científicos dos quais toma referentes epistemológicos e culturais para definir suas bases e características. A pedagogia universitária é um espaço de conexão de conhecimentos, subjetividades e cultura, que exige um conteúdo científico, tecnológico ou artístico altamente especializado e orientado para a formação de uma profissão (LUCARELI, 2000, p. 36). Pressupõe, especialmente, conhecimentos no âmbito do currículo e da prática pedagógica que inclui as formas de ensinar e aprender. Incide sobre as teorias e as práticas de formação de professores e dos estudantes da educação superior. Articula as dimensões do ensino e da pesquisa nos lugares e espaços de formação. Pode envolver uma condição institucional considerando-se como pedagógicos o conjunto de processos vividos no âmbito acadêmico (CUNHA, 2006, p. 351).

\section{Referências}

ARNAUS, Remei. Voces que cuentam y vocês que interpretam. In: LARROSA, Jorge; ARNAUS, Remei; FERRER, Virginia et al. Déjame que te cuente. Barcelona: Alertes, 1995, p. 61-78.

ABRAHAM, Ada (Org.). El enseñante es también una persona. Barcelona: Gedisa, 2000.

. El mundo interior de los enseñantes. Barcelona: Gedisa, 1987.

BAUER, Martin. Análise de conteúdo clássica: uma revisão. In: BAUER, Martin; GASKELL, George. Pesquisa qualitativa com texto, imagem e som. Um manual prático. Petrópolis: Vozes, 2004, p. 189-217.

BOLZAN, Doris Pires Vargas. Formação de professores: compartilhando e reconstruindo conhecimentos. Porto Alegre: Mediação, 2002.

A construção do conhecimento pedagógico compartilhado: reflexões sobre o papel do professor universitário. In: ANAIS da V ANPEd Sul, Curitiba/PR, 2004. p. 1-15.

Verbete. In: CUNHA, Maria Isabel; ISAIA, Silvia de Aguiar. Professor da educação superior. In: MOROSINI, Marília (Ed.). Enciclopédia de pedagogia universitária: glossário. Brasília, v. 2, 2007. p. 388.

BOLZAN, Dóris Pires Vargas; ISAIA, Silvia de Aguiar. Aprendizagem docente na educação superior: construçôes tessituras da professoralidade. Revista Educação. Porto Alegre: EDIPUCRS, v. 29, n. 3 (60) p. 489-501, 2006.

BRUN, Patrick; BACHELART, Dominique. Histoires de vie et démarches collectives de 
construction d'histoire. Education Permanente. Paris, n. 142, p. 105-114, 2000.

CONNELLY, Michael; CLANDININ, Jean. Relatos de experiência e investigación narrativa. In: LARROSA, Jorge; ARNAUS, Remei; FERRER, Virginia et al. Déjame que te cuente. Barcelona: Alertes, 1995, p. 53-78.

CUNHA, Maria Isabel. Verbete. In: CUNHA, Maria Isabel; ISAIA, Silvia de Aguiar. Professor da Educação Superior. In: MOROSINI, Marília (Ed.). Enciclopédia de pedagogia universitária: glossário. Brasília, v. 2, 2006. p. 351.

HUBERMAN, Michael. La vie des enseignants. Évolution et bilan d'une profession. Paris/ Neuchâtel: Delachaux et Niestlé, 1989.

Trabajando con narrativas biográficas. In: McEWAN, Hunter; EGAN, Kieran (Comps.). La narrativa en la enseñanza el aprendizaje y la investigación. Buenos Aires: Amorrortu, 1998. p. 183-235.

ISAIA, Silvia de Aguiar. Professor do ensino superior: tramas na tessitura. In: MOROSINI, Marília (Org.). Enciclopédia de pedagogia universitária. Porto Alegre: FAPERGS/ RIES, 2003. p. 241-251.

. Desafios à Docência Superior: pressupostos a considerar. In: RISTOFF, Dilvo; SEVEGNANI, Palmira (Orgs.). Docência na educação superior. Brasília: Inep, 2006a, p. 65-86. (Coleção Educação Superior em Debate; v. 5).

Verbetes. In: CUNHA, Maria Isabel; ISAIA, Silvia de Aguiar. Professor da Educação Superior. In: MOROSINI, Marília (Ed.). Enciclopédia de pedagogia universitária: glossário. Brasília, v. 2, 2006b, p. 358, 368, 373, 377.

ISAIA, Silvia de Aguiar; BOLZAN, Dóris Pires Vargas. Tessituras dos processos formativos de professores que atuam nas licenciaturas. In: RAYS, Oswaldo A. (Org.). Educação, matemática e física: subsídios para a prática pedagógica. Santa Maria, RS: Edunifra, 2006, p. 69-86.

Ciclos de vida profissional docente: movimentos construtivos da docência universitária. In: Anais IV Congresso Nacional y II Internacional de Investigación Educativa, Universidad Nacional de Comahue, Argentina, 2007a. p. 1-13.

. Construção da Profissão docente/professoralidade em debate: desafios para a educação superior. In: CUNHA, Maria Isabel (Org.). Reflexões e práticas em pedagogia universitária. Campinas: Papirus, 2007b, p. 161-177.

LANI-BAYLE, Martine. Histoire de vie et transmission intergénérationnelle. Education Permanente. Paris, n. 142, p. 85-93, 2000.

LUCARELLI, Elisa (Comp.). El asesor pedagógico em la universidad. De la teoria pedagógica a la práctica en la formación. Buenos Aires: Paidos, 2000.

LUDKE, Menga. Os professores e a sua socialização profissional. In: REALI, Aline Maria de Medeiros; MIZUKAMI, Maria da Graça (Org.). Formação de professores. São Carlos: EDUFSCar, 1996. p. 25-46.

MARCELO, Carlos Garcia. Formación del professorado para el cambio educativo. Barcelona: EUB, 1999.

McEWAN, Hunter. Las narrativas en el estudio de la docência. In: McEWAN, Hunter; EGAN, Kibran (Comps). La narrativa en la enseñanza, el aprendizaje y la investigación. Buenos Aires: 
Amorrortu, 1998. p. 236-259.

MIZUKAMI, Maria da Graça. Aprendendo a profissão docente no ensino superior: um estudo de caso. São Carlos: PPGE - UFSCar, 1995.

Docência, trajetórias pessoais e desenvolvimento profissional. In: REALI, Aline Maria de Medeiros; MIZUKAMI, Maria da Graça (Orgs.). Formação de professores. São Carlos: EDUFSCar, 1996, p. 59-91.

MORAES, Roque. Uma experiência de pesquisa coletiva: introdução à Análise de Conteúdo. In: GRILlO, Marlene; MEDEIROS, Marilu. Construção do conhecimento e sua mediação metodológica. Porto Alegre: EDIPUCRS, 1998, p. 111-129.

ORTEGA Y GASSET, José. Obras completas. 7. ed. Madrid: Ediciones de la Revista del Occidente, 1970 , v. 5.

PROJETO DE PESQUISA. O professor de licenciatura e a docência: reflexões e posicionamentos ao longo da carreira. CNPq, 1999 - 2003.

PROJETO DE PESQUISA. Ciclos de vida de professores do ensino superior: um estudo sobre trajetórias docentes. CNPq, 2003 - 2007.

PROJETO DE PESQUISA. O aluno/professor do Curso de Pedagogia e a alfabetização: construçōes pedagógicas e epistemológicas da formação profissional. FAPERGS, $2002-2005$.

PROJETO DE PESQUISA. Aprendizagem docente e processos formativos: novas perspectivas para a educação básica e superior. GAP n. 020117, CE/UFSM, FAPERGS, 2007 - 2009.

ZABALZA, Miguel. O ensino universitário: seu cenário e seus protagonistas. Porto Alegre: Artmed, 2004. 


\section{Understanding the constructive movements of higher education teaching: constructions over university pedagogy Abstract}

This article result from the researches which have been developed by the authors and, specially, on the thematic of the professional life cycles of higher education professors. It discusses the possible constructive movements in the teaching trajectory of university professors. The present discussion emerges from the search for comprehension of the constructive movements of teaching, as well as the delineation of possible professional life cycles of these subjects. The participants in the research were grouped according to experience in the higher education teaching, aiming to describe their biographies. In this analysis four teaching constructive movements were found: the preparation for the teaching career, effective entrance in higher education teaching, post-graduation traces in higher education teaching; teaching professorality. The findings allow us to speculate that the teaching conception threads are woven from constructive movements throughout the teaching trajectory, marking them out as a continuous learning process for teaching.

Keywords: University pedagogy. Constructive movements. Higher education teaching.

\section{Comprenant les mouvements constructifs de l'enseignement universitaire : constructions sur la pédagogie universitaire \\ Résumé}

Cet article découle de recherches que les auteurs ont développé, en particulier, sur la thématique des cycles de vie professionnelle de professeurs de l'enseignement supérieur. Il discute les possibles mouvements constructifs de la vie professionnelle de ces sujets. Les participants de la recherche ont été regroupés en tenant compte du temps d'expérience dans le magistère supérieur, ayant comme finalité la narration de leurs biographies. Dans cette analyse, nous avons rencontré quatre mouvements constructifs du magistère : préparation à la carrière du magistère ; entrée effective dans le magistère supérieur ; marques des études post baccalauréat sur le magistère supérieur; professeuralité des professeurs. Les résultats nous permettent de spéculer que les fils des conceptions du magistère sont tissés à partir des mouvements constructifs au long de la trajectoire du professeur, les démarquant comme un processus continu d'apprentissage du magistère.

Mots clefs : Pédagogie universitaire. Mouvements constructifs. Magistère supérieur.

\section{Comprendiendo los movimientos constructivos de la docencia superior: construcciones sobre pedagogía universitaria \\ Resumen}

Ese artículo es resultado de investigaciones desarrolladas por las autoras, en especial las relativas a los ciclos de vida profesional de profesores de la enseñanza superior. Discute los posibles movimientos constructivos en la trayectoria docente de profesores universitarios. Esa discusión ocurre a partir de la búsqueda por la comprensión de los movimientos contractivos de la docencia, bien como del delineamiento de posibles ciclos de vida profesional de eses sujetos. Los participantes de la pesquisa feron agrupados considerándose el tiempo de experiencia en el magisterio superior, con la finalidade de narrar sus biografias la docencia: preparación a la carrera docente; entrada efectiva en el magisterio superior; marcas del posgrado en la docencia superior; profesoralidad docente. Los resultados nos permiten especular que los hilos de las concepciones de docencia son tejidos a partir de los movimientos contructivos al largo de la trayectoria docente, demarcándolos como un proceso continuo de aprendizade docente.

Palabras-clave: Pedagogía universitaria. Movimentos constructivos. Docencia superior. 
